\title{
Phytic acid increases mucin and endogenous amino acid losses from the gastrointestinal tract of chickens
}

\author{
Edward M. Onyango ${ }^{1}$, Elikplimi K. Asem ${ }^{2}$ and Olayiwola Adeola ${ }^{3}$ \\ ${ }^{1}$ Department of Health Sciences, East Tennessse State University, Box 70673, Johnson City, TN 37614, USA \\ ${ }^{2}$ Department of Basic Medical Sciences, Purdue University, West Lafayette, IN 47907, USA \\ ${ }^{3}$ Department of Animal Sciences, Purdue University, West Lafayette, IN 47907, USA
}

(Received 4 March 2008 - Revised 21 May 2008 - Accepted 17 June 2008 - First published online 2 September 2008)

The influence of the form of phytic acid on the regulation of mucin and endogenous losses of amino acids, nitrogen and energy in chickens was investigated. Forty-eight 10 -week-old male broilers were grouped by weight into eight blocks of six cages with one bird per cage. Birds received by intubation six dextrose-based combinations of phytic acid and phytase arranged in a $3 \times 2$ factorial consisting of phytic acid form (no phytic acid, $1.0 \mathrm{~g}$ free phytic acid or $1.3 \mathrm{~g}$ magnesium-potassium phytate) and phytase ( 0 or 1000 units). Each bird received the assigned combination added to $25 \mathrm{~g}$ dextrose at each of the two feedings on the first day of experimentation. All excreta were collected continuously for $54 \mathrm{~h}$ following feeding and frozen until analysed. Frozen excreta were thawed, pooled for each bird, lyophilised, ground, and analysed for DM, energy, nitrogen, amino acids, mucin, and sialic and uric acids. Chickens fed either magnesium-potassium phytate or free phytic acid showed increased $(P<0.05)$ loss of crude mucin and sialic acid. The amount of crude mucin lost was significantly greater $(P<0.05)$ with magnesiumpotassium phytate than with free phytic acid treatment. Both phytic acid treatments also increased $(P<0 \cdot 05)$ endogenous loss of threonine, proline and serine. In conclusion, the form of phytic acid fed to chickens affects the extent of mucin and endogenous amino acid losses from the gastrointestinal tract.

Chickens: Endogenous loss: Mucin: Phytic acid

Phytic acid (inositol hexaphosphate, myo-inositol 1,2,3,4,5, 6-hexakis (dihydrogen phosphate)) is a naturally occurring phytochemical common in foods such as nuts, legumes, cereals and in all seeds ${ }^{(1)}$. It occurs in plants as a mixed salt of mainly magnesium and potassium ${ }^{(2)}$. Phytic acid is a moderately strong acid with twelve ionisable protons whose $\mathrm{pK}_{\mathrm{a}}$ values range from 1 to $12^{(3)}$. Over a wide $\mathrm{pH}$ range the phytate ion has the capacity to chelate various cations between two phosphate groups or weakly within a phosphate group ${ }^{(4)}$. The ability of phytates to form complexes with proteins and other nutrients is thought to be one of the mechanisms which exerts their antinutritional effects. Complexing with proteins may lead to increased amino acid losses. Such loss has been suggested as a possible explanation for the reduced overall amino acid digestibility observed when wheat pentosans were fed to chickens by crop intubation ${ }^{(5)}$. The chelating ability may also explain the ability of phytates to directly or indirectly inhibit some enzymes. Inhibition of enzymes such as lipase ${ }^{(6)}$ and $\alpha$-amylase ${ }^{(7)}$ is thought to occur via direct chelation of the enzyme by formation of phytate-protein complexes. On the other hand, the inhibition of pepsin seems to result from phytates altering the solubility and structure of the substrate so that the ability of pepsin to act on the substrate is reduced ${ }^{(8,9)}$. More recently, some studies have shown that phytate feeding is accompanied by increased loss of not only amino acids but also constituents of mucins such as sialic acid. For example, an increase in endogenous loss of amino acids, minerals and sialic acid has been reported when chickens were fed phytic acid in the form of sodium phytate $^{(10,11)}$. It was further demonstrated that the addition of exogenous phytase reduced the loss of amino acids, minerals and sialic acid caused by phytic acid feeding ${ }^{(10,11)}$. Because phytic acid occurs in plant foods as a mixed salt of mainly magnesium and potassium, intestinal endogenous effects of different forms and/or salts of phytic acid may be more nutritionally relevant. Thus, it is of nutritional interest to know whether the forms of phytic acid (as free acid or magnesium-potassium phytate salt) exert different effects on mucin and other endogenous losses. It is hypothesised that the effects, on endogenous losses, of magnesium-potassium phytate would be different from those of the free acid. The effects of magnesium-potassium phytate, the salt closest to the natural form of phytic acid, would more accurately show the effects of dietary phytates on endogenous losses than would the free acid. The objective of the present study was, therefore, to investigate the effects of two different forms of phytic acid (free acid and magnesium-potassium phytate salt) on endogenous losses of mucin, amino acids, nitrogen and energy in chickens, and to assess whether exogenous dietary phytase ameliorates these effects. 


\section{Materials and methods}

\section{General procedures}

Forty-eight 10-week-old male broilers (Ross-308) were used in the study. The birds were wing-banded and fitted with screw caps on their vents, on to which collection bags for excreta were attached later during the actual collection procedure ${ }^{(12)}$. They were individually weighed, arranged in descending body weight and grouped into eight blocks of six cages each with one bird per cage and assigned to six dietary treatments in a randomised complete block design. Two dietary factors including three phytic acid forms (no phytic acid, $1.0 \mathrm{~g}$ free phytic acid (phytic acid solution, $50 \%$ w/w in water; SigmaAldrich Corp., St Louis, MO, USA, catalogue no. 593648) or $1.3 \mathrm{~g}$ magnesium-potassium phytate (phytic acid magnesium potassium salt; Sigma-Aldrich Corp., St Louis, MO, USA, catalogue no. P7660)), and two phytase levels (0 or 1000 units; Phyzyme XP, Danisco Animal Nutrition, Marlborough, UK) were arranged in a $3 \times 2$ factorial. The $1.3 \mathrm{~g}$ magnesiumpotassium phytate contained an equivalent of $1.0 \mathrm{~g}$ free acid. When both forms of phytic acid ionise, they produce the phytate ion which consists of an inositol ring with six phosphates and has a strong chelating ability. Phyzyme XP phytase used in the study is an Escherichia coli-derived 6-phytase (EC 3.1.3.26) produced in Schizosaccharomyces pombe. Each of the six treatments contained $25 \mathrm{~g}$ dextrose at each feeding and birds were fed twice on the day of dosing (Table 1). Each bird received an equivalent of $2 \mathrm{~g}$ free phytic acid during the dosing day. The amount of phytic acid fed was a conservative estimate of the amount of phytate that 10-week-old male broilers are likely to consume per day. A 10-week-old male broiler can consume at least $230 \mathrm{~g}$ feed per day ${ }^{(13)}$. Reddy et al. ${ }^{(14)}$ have estimated that phytates may constitute up to $30 \mathrm{~g} / \mathrm{kg}$ of plant ingredients used in monogastric diets. Therefore, depending on the diet, a 10 -week-old male broiler can consume as much as $6.9 \mathrm{~g}$

Table 1. Experimental protocol for feeding and excreta collection in 10 -week-old male broilers fed dextrose-based combinations of phytic acid and phytase

\begin{tabular}{|c|c|}
\hline Time (h) & Operation \\
\hline 0 & $\begin{array}{l}\text { Birds weighed, assigned to diets, feed withdrawn. Birds } \\
\text { allowed access ad libitum to water. }\end{array}$ \\
\hline 24 & $\begin{array}{l}\text { Birds placed in assigned cages. Each bird fed dextrose } \\
\text { solution ( } 25 \mathrm{~g} \text { in } 50 \mathrm{ml} \text { water). }\end{array}$ \\
\hline 30 & Each bird fed dextrose solution ( $25 \mathrm{~g}$ in $50 \mathrm{ml}$ water). \\
\hline 48 & $\begin{array}{l}\text { Birds fed assigned dextrose-based material (in } 50 \mathrm{ml} \text { water). } \\
\text { Collection bags screwed on to attached lids. }\end{array}$ \\
\hline 54 & $\begin{array}{l}\text { Birds fed assigned dextrose-based material (in } 50 \mathrm{ml} \text { water). } \\
\text { Excreta collected and frozen. New collection bags } \\
\text { screwed into lids. Birds allowed access ad libitum } \\
\text { to water for } 3 \mathrm{~h} \text {. }\end{array}$ \\
\hline 60 & $\begin{array}{l}\text { Excreta collected and frozen. New collection bags screwed } \\
\text { into lids. }\end{array}$ \\
\hline 72 & $\begin{array}{l}\text { Excreta collected and frozen. New collection bags screwed } 0 \\
\text { into lids. }\end{array}$ \\
\hline 84 & $\begin{array}{l}\text { Excreta collected and frozen. New collection bags screwed } \\
\text { into lids. Birds allowed access ad libitum to water for } 3 \mathrm{~h} \text {. }\end{array}$ \\
\hline 96 & $\begin{array}{l}\text { Excreta collected and frozen. New collection bags screwed } \\
\text { into lids. Birds allowed access ad libitum to water for } 3 \mathrm{~h} \text {. }\end{array}$ \\
\hline 102 & Excreta collected and frozen. Lids removed. \\
\hline
\end{tabular}

phytate/d. Hence a consumption of $2 \mathrm{~g}$ phytate/d would be a conservative estimate of the amount of phytate such a broiler is most likely to consume even in the likelihood that there are low levels of phytates in the diet. All housing and handling procedures were approved by the Purdue University Animal Care and Use Committee.

\section{Experimental protocol}

The experimental protocol followed is outlined in Table 1. Feed was withdrawn from the birds for $24 \mathrm{~h}$. Birds were force-fed, by crop intubation, dextrose solution $(25 \mathrm{~g}$ in $50 \mathrm{ml}$ water) at 24 and $30 \mathrm{~h}$ after feed was withdrawn. At 48 and $54 \mathrm{~h}$ following feed withdrawal they were fed their assigned dextrose-based combinations of phytic acid and phytase in $50 \mathrm{ml}$ water. All birds were fitted with an excreta collection bag, at the initial time (at $48 \mathrm{~h}$ ) of feeding the assigned dextrose-based combinations, as previously described by Adeola et al. ${ }^{(12)}$. Collection bags were changed within the first $6 \mathrm{~h}$ after placement and every $6-12 \mathrm{~h}$ thereafter during the $54 \mathrm{~h}$ collection period (Table 1). Collected excreta were immediately frozen at $-20^{\circ} \mathrm{C}$ until further processing.

\section{Analytical procedures}

Frozen excreta were thawed, pooled for each bird, lyophilised, ground to pass through a $0.5 \mathrm{~mm}$ screen, and thoroughly mixed before analysis for DM, energy, nitrogen, amino acids, mucin, and sialic and uric acids. Samples of excreta were oven-dried at $100^{\circ} \mathrm{C}$ for $12 \mathrm{~h}$ for $\mathrm{DM}$ determination. Nitrogen in the samples was determined by the combustion method using a combustion analyser (Leco Model FP 2000; Leco Corp., St. Joseph, MI, USA). Analysis for amino acid content of samples was conducted at the University of Missouri Experiment Station Chemical Laboratory. Samples were hydrolysed in hydrochloric acid followed by HPLC (AOAC procedure no. $\left.982.30 \mathrm{E}(\mathrm{a}, \mathrm{b}, \mathrm{c})^{(15)}\right)$. Samples for tryptophan determination were hydrolysed using barium hydroxide and those for determination of methionine and cysteine were oxidised in performic acid followed by hydrochloric acid hydrolysis. Gross energy content of samples was determined by bomb calorimetry using an adiabatic calorimeter (Parr 1261 bomb calorimeter; Parr Instruments Co., Moline, IL, USA).

Crude mucin in the samples was prepared from lyophilised excreta samples using a modification of the method described by Lien et al. ${ }^{(16)}$. Lyophilised samples (1 g) and $15 \mathrm{ml}$ $0 \cdot 15 \mathrm{M}-\mathrm{NaCl}$ were placed into $50 \mathrm{ml}$ plastic centrifuge tubes maintained at $2^{\circ} \mathrm{C}$. Samples were homogenised for $1 \mathrm{~min}$ using a polytron homogeniser followed by centrifugation at $16100 \mathrm{~g}$ at $2^{\circ} \mathrm{C}$ for $30 \mathrm{~min}$. A $10 \mathrm{ml}$ aliquot of the supernatant was pipetted into a pre-weighed $50 \mathrm{ml}$ centrifuge tube and mixed with $15 \mathrm{ml}$ ice-cold absolute ethanol. The mixture was kept overnight to extract at $-20^{\circ} \mathrm{C}$, centrifuged at $1400 \mathrm{~g}$ at $2^{\circ} \mathrm{C}$ for $10 \mathrm{~min}$, and the supernatant was discarded. The pellet was solubilised in $10 \mathrm{ml} 0.15 \mathrm{M}-\mathrm{NaCl}$, cooled in an ice-bath before the addition of $15 \mathrm{ml}$ pre-cooled absolute ethanol. The mixture was kept overnight to extract at $-20^{\circ} \mathrm{C}$, centrifuged at $1400 \mathrm{~g}$ at $2^{\circ} \mathrm{C}$ for $10 \mathrm{~min}$, and the supernatant was discarded. This rinsing procedure was repeated. The tube 
containing the pellet was turned upside down, allowed to drip-dry and weighed to get the weight of crude mucin yield, followed by solubilising the pellet in $2 \mathrm{ml}$ doubledistilled water.

Sialic acid in the crude mucin samples was determined using a modification of the method described by Surangkul et al. ${ }^{(17)}$ which is based on the earlier method described by Jourdian et al. ${ }^{(18)}$ and later modified by Bhavanandan \& Sheykhmazari ${ }^{(19)}$. In our method, the mixture of periodic acid and the sample was kept on ice for 35 min instead of $60 \mathrm{~min}$ as described by Surangkul et al. ${ }^{(17)}$. In the method, periodic acid oxidises sialic acids and their glycosides into a light yellow chromogen. The chromogen product reacts with Svennerholm resorcinol reagent to develop a blue colour, whose absorbance at $620 \mathrm{~nm}$ is proportional to the sialic acid concentration in the sample.

$N$-Acetylneuraminic acid ( $40 \mu \mathrm{l} ; 0-9.5 \mu \mathrm{g} /$ well $)$ or dissolved samples were added into wells of a ninety-six-well microtitre plate. Freshly prepared $1.3 \mathrm{~mm}$-periodic acid $(50 \mu \mathrm{l})$ was added to each well and mixed for $5 \mathrm{~min}$ at room temperature using a plate shaker. The mixture was incubated on ice for $35 \mathrm{~min}$ to allow for oxidation of the sialic acids, followed by the addition of $100 \mu$ f freshly prepared resorcinol reagent $(6 \mathrm{~g} / \mathrm{l})$ and then mixed for $5 \mathrm{~min}$ at room temperature using a plate shaker. The plate was covered and heated at $80^{\circ} \mathrm{C}$ for $60 \mathrm{~min}$ in a water-bath. Immediately thereafter, the plate contents were cooled and mixed for $2 \mathrm{~min}$ at room temperature then $100 \mu \mathrm{l} 95 \%$ 2-methyl-propan-2-ol was added to enhance and stabilise the colour. The contents were mixed by shaking on a plate mixer for $5 \mathrm{~min}$ at room temperature and subsequently read at an absorbance of $620 \mathrm{~nm}$.

Uric acid content of the excreta samples was determined as follows: lyophilised samples $(0.1 \mathrm{~g})$ and $15 \mathrm{ml} 1.0 \mathrm{M}-\mathrm{Na}_{2} \mathrm{CO}_{3}$ were placed into $50 \mathrm{ml}$ plastic centrifuge tubes. Samples were homogenised for $1 \mathrm{~min}$ using a polytron homogeniser then centrifuged at $16100 \mathrm{~g}$ at $2^{\circ} \mathrm{C}$ for $30 \mathrm{~min}$. The supernatant was decanted into pre-labelled $15 \mathrm{ml}$ tubes. From each sample, a $5 \mathrm{ml}$ aliquot was pipetted into a different $15 \mathrm{ml}$ tube and $5.525 \mathrm{ml} \mathrm{3.0} \mathrm{M-2-amino-2-hydroxymethyl-1,3-propa-}$ nediol hydrochloride buffer was added to lower the $\mathrm{pH}$ to $8 \cdot 25$. The samples were subsequently diluted five to ten times prior to the determination of uric acid content using a commercial kit (ThermoTrace uric acid kit no. TR24321; Thermo DMA, Louisville, CO, USA). In the procedure, uric acid is oxidised to allantoin and hydrogen peroxide. The peroxide reacts with 4-aminoantipyrine and 2,4,6-tribromo-3-hydroxybenzoic acid in the presence of peroxidase to yield a pink quinoneimine dye. The resulting change in absorbance at $550 \mathrm{~nm}$ is proportional to the uric acid content in the sample.

\section{Calculations}

Amounts of excreta collected were corrected for the total uric acid content by subtracting total uric acid from the total excreta collected. This was to reduce variation that may occur due to differences in levels of uric acid excreted by the different birds. Concentrations of energy, nitrogen, amino acids, crude mucin and sialic acid in excreta were multiplied by the corrected total excreta to obtain the total amount of nutrients or compounds excreted. Amino acid losses were expressed both as total amounts and as a proportion of the total endogenous crude protein lost. Expressing amino acids as a proportion of endogenous protein may indicate if the treatments imposed caused a shift in composition of endogenous proteins lost. The amino acid proportions of endogenous protein were calculated as follows: total nitrogen was multiplied by 6.25 to obtain the total endogenous crude protein; the proportion $(\%)$ of crude protein excreted as a particular amino acid was obtained by dividing the amount of amino acid by the total endogenous crude protein and then multiplying by 100 .

\section{Statistical analysis}

Data were analysed using two-way ANOVA using the GLM procedures of the Statistical Analysis Systems statistical package release 8.1 (SAS Institute, Cary, NC, USA) appropriate for a randomised complete block design. The individual bird was the experimental unit. The level of statistical significance was set at $P<0 \cdot 05$. Means were separated using orthogonal contrasts.

\section{Results}

The amount of uric acid excreted by the chickens showed a trend $(P=0.07)$ towards being affected by the form of phytic acid (Table 2). Chickens intubated with either form of phytic acid tended to excrete more uric acid $(0 \cdot 41 \mathrm{~g})$ compared with those that did not receive phytic acid $(0.28 \mathrm{~g})$.

Table 2. Main effect means of the form of phytic acid and supplemental phytase on total energy, nitrogen, crude mucin and sialic acid (units/bird per $54 \mathrm{~h}$ ) excreted by 10 -week-old male broilers fed dextrose-based combinations of phytic acid and phytaseł

\begin{tabular}{|c|c|c|c|c|c|c|}
\hline \multirow[b]{2}{*}{ Item } & \multicolumn{3}{|c|}{ Phytic acid form } & \multicolumn{2}{|c|}{ Phytase (units) } & \multirow[b]{2}{*}{ Pooled SEM } \\
\hline & No phytic acid & Free phytic acid & Magnesium-potassium phytate & 0 & 1000 & \\
\hline$n$ & 16 & 16 & 16 & 24 & 24 & \\
\hline Energy (kJ) & $141 \cdot 9$ & $145 \cdot 8$ & $148 \cdot 7$ & $147 \cdot 9$ & 143.0 & 8.9 \\
\hline Nitrogen (g) & $2 \cdot 13$ & 2.08 & 1.99 & $2 \cdot 12$ & 2.02 & 0.13 \\
\hline Crude mucin (g) & 3.05 & $4.57^{\star}$ & $8 \cdot 00^{*} \dagger$ & 5.55 & 4.87 & 0.64 \\
\hline Sialic acid (mg) & 0.30 & $0.59^{\star}$ & $0.49^{\star}$ & 0.41 & 0.50 & 0.08 \\
\hline Uric acid $(\mathrm{g})$ & 0.28 & 0.37 & 0.44 & 0.34 & 0.39 & 0.06 \\
\hline
\end{tabular}

Mean values of the average of the 'Free phytic acid' and 'Magnesium-potassium phytate' groups were significantly different from those of the 'No phytic acid' group: ${ }^{\star} P<0.05$. Mean value was significantly different from that of the 'Free phytic acid' group: $\uparrow P<0.05$.

¥For details of procedures, see Materials and methods section and Table 1. Values of energy, nitrogen, crude mucin and sialic acid were calculated using excreta values that had been corrected for uric acid. 
There was no interaction $(P>0.05)$ between phytic acid form and phytase on mucin, sialic acid, energy, nitrogen and amounts of amino acids excreted (Tables 2-4); hence only the main effect means for mucin, sialic acid, energy, nitrogen and amino acids are presented.

The effect of the form of phytic acid was significant $(P<0 \cdot 05)$ for crude mucin and sialic acid in the excreta (Table 2). Chickens intubated with phytic acid had more $(P<0 \cdot 05)$ crude mucin and sialic acid in their excreta ( 6.3 and $0.54 \mathrm{~g}$, respectively) compared with those that were not given any phytic acid $(3.1$ and $0.30 \mathrm{~g}$, respectively; Table 2). The increase in crude mucin was greater $(P<0.05)$ in the magnesium-potassium phytate group $(8.00 \mathrm{~g})$ compared to the free phytic acid group $(4.57 \mathrm{~g})$. Total energy and nitrogen excreted by the bird were not affected by the form of phytic acid (Table 2).

There was no mucin or sialic acid secretion response to phytase supplementation. Also the addition of microbial phytase did not affect the amount of energy, or nitrogen excreted by the chickens (Table 2).

Chickens that received free phytic acid or magnesium-potassium phytate excreted more $(P<0.05)$ threonine $(84 \mathrm{mg})$, proline $(116 \mathrm{mg})$ and serine $(75 \mathrm{mg})$ compared with the no-phytic acid group (69, 96 and $63 \mathrm{mg}$, respectively; (Table 3). On the other hand, when amino acid loss was expressed as a proportion of the total crude protein, a similar trend in the amino acid loss was noted (Table 4). Phytic acid treatment increased the proportion (\%) of crude protein lost as arginine, threonine, glycine, proline and serine from 0.42 , $0.53,2.18,0.72$ and 0.47 to $0.55,0.68,2.67,0.93$ and 0.61 , respectively. The proportion of histidine, lysine, phenylalanine, tryptophan, alanine, aspartate, cysteine and glutamate also showed a trend towards increased loss when birds received the phytic acid treatment (Table 4).
Phytase supplementation did not affect the amount of amino acids excreted, regardless of whether they were expressed as total amounts or as a proportion of the crude protein (Tables 3 and 4).

\section{Discussion}

Endogenous losses form the portion of excreta which comes from the animal itself and is not of dietary origin. These endogenous losses consist mainly of sloughed cells and secretions from the digestive tract. In the present study, changes in mucins, energy, nitrogen and amino acids were used as indicators of endogenous loss in response to feeding various forms of phytic acid with or without supplemental microbial phytase. Mucins are among the indicators used for endogenous losses in the present study. They are large glycoproteins that make up the structure of mucus that cover epithelial cells lining ducts such as the digestive tract ${ }^{(20)}$. The glycoproteins are composed of peptide backbones that have highly glycosylated domains rich in proline, threonine and serine ${ }^{(21)}$. Because mucins have a peptide core, it would follow that a change in the quantity of mucins lost would directly affect the quantity of amino acids lost ${ }^{(16)}$.

Phytates in the diets of non-ruminant animals are considered to be anti-nutritional in their effects because they reduce the digestion and absorption of nutrients by the animal. These effects are mediated by the phytate ion, which because of its twelve ionisable protons, whose $\mathrm{pK}_{\mathrm{a}}$ values range from 1 to 12 , has a capacity to chelate various cations between two phosphate groups or weakly within a phosphate group ${ }^{(3,4)}$. This, therefore, allows the phytate ion to form complexes with a variety of nutrients in feedstuffs or in the gut ${ }^{(4,2)}$. It is the formation of such complexes that might reduce the digestion of complexed

Table 3. Main effect means of the form of phytic acid and supplemental phytase on total amino acids (mg/bird per $54 \mathrm{~h}$ ) excreted by 10 -week-old male broilers fed dextrose-based combinations of phytic acid and phytase $\neq$

\begin{tabular}{|c|c|c|c|c|c|c|}
\hline \multirow[b]{2}{*}{ Item } & \multicolumn{3}{|c|}{ Phytic acid form } & \multicolumn{2}{|c|}{ Phytase (units) } & \multirow[b]{2}{*}{ Pooled SEM } \\
\hline & No phytic acid & Free phytic acid & Magnesium-potassium phytate & 0 & 1000 & \\
\hline$n$ & 16 & 16 & 16 & 24 & 24 & \\
\hline \multicolumn{7}{|l|}{ Indispensable amino acids } \\
\hline Arginine & $55 \cdot 6$ & 67.5 & $66 \cdot 9$ & $66 \cdot 3$ & $60 \cdot 4$ & $5 \cdot 80$ \\
\hline Histidine & $30 \cdot 6$ & 39.4 & $40 \cdot 6$ & 40.4 & 33.3 & 6.51 \\
\hline Isoleucine & $46 \cdot 3$ & $51 \cdot 3$ & 51.9 & $52 \cdot 1$ & 47.5 & $5 \cdot 20$ \\
\hline Leucine & $75 \cdot 6$ & $85 \cdot 6$ & $85 \cdot 0$ & $86 \cdot 7$ & 77.5 & 7.81 \\
\hline Lysine & 67.5 & $79 \cdot 4$ & $75 \cdot 6$ & $77 \cdot 1$ & 71.3 & $7 \cdot 81$ \\
\hline Methionine & $19 \cdot 4$ & $21 \cdot 3$ & 22.5 & $22 \cdot 1$ & $20 \cdot 0$ & 2.93 \\
\hline Phenylalanine & 47.5 & 53.8 & 53.8 & $54 \cdot 2$ & $49 \cdot 2$ & 4.95 \\
\hline Threonine & $68 \cdot 8$ & $85 \cdot 0^{*}$ & $83 \cdot 8^{\star}$ & $81 \cdot 7$ & $76 \cdot 7$ & $6 \cdot 43$ \\
\hline Tryptophan & $16 \cdot 3$ & $16 \cdot 9$ & $16 \cdot 3$ & $16 \cdot 3$ & $16 \cdot 7$ & 1.80 \\
\hline Valine & $63 \cdot 1$ & 71.3 & $70 \cdot 0$ & $71 \cdot 3$ & $65 \cdot 0$ & 6.72 \\
\hline \multicolumn{7}{|l|}{ Dispensable amino acids } \\
\hline Alanine & $78 \cdot 1$ & $88 \cdot 1$ & $88 \cdot 1$ & 87.9 & $81 \cdot 7$ & 8.24 \\
\hline Aspartate & $113 \cdot 8$ & $135 \cdot 0$ & 132.5 & $132 \cdot 1$ & $122 \cdot 1$ & $11 \cdot 17$ \\
\hline Cysteine & $35 \cdot 0$ & 36.9 & 37.5 & $36 \cdot 7$ & $36 \cdot 3$ & 3.11 \\
\hline Glutamate & $180 \cdot 6$ & $205 \cdot 0$ & $205 \cdot 6$ & $202 \cdot 9$ & $191 \cdot 3$ & $16 \cdot 48$ \\
\hline Glycine & $290 \cdot 6$ & 333.8 & $343 \cdot 8$ & $329 \cdot 2$ & $316 \cdot 3$ & $28 \cdot 92$ \\
\hline Proline & $95 \cdot 6$ & $119 \cdot 4^{*}$ & $113 \cdot 1^{*}$ & 107.5 & 111.3 & 8.84 \\
\hline Serine & 62.5 & $75 \cdot 0^{\star}$ & $75 \cdot 6^{\star}$ & $72 \cdot 1$ & $70 \cdot 0$ & $5 \cdot 69$ \\
\hline Tyrosine & 41.3 & $45 \cdot 6$ & $45 \cdot 0$ & $46 \cdot 7$ & 41.3 & 4.74 \\
\hline Total of all amino acids & $1525 \cdot 6$ & $1765 \cdot 0$ & 1791.9 & $1739 \cdot 6$ & $1648 \cdot 8$ & $12 \cdot 55$ \\
\hline
\end{tabular}

Mean were of the average of the 'Free phytic acid' and 'Magnesium-potassium phytate' groups were significantly different from those of the 'No phytic acid' group: ${ }^{\star} P<0.05$. $\ddagger$ For details of procedures, see Materials and methods section and Table 1. Values were calculated using excreta values that had been corrected for uric acid. 
Table 4. Main effect means of the form of phytic acid and supplemental phytase on the proportion (\%) of total crude protein excreted as amino acids (per bird/54h) by 10 -week-old male broilers fed dextrose-based combinations of phytic acid and phytaseł

\begin{tabular}{|c|c|c|c|c|c|c|}
\hline \multirow[b]{2}{*}{ Item } & \multicolumn{3}{|c|}{ Phytic acid form } & \multicolumn{2}{|c|}{ Phytase (units) } & \multirow[b]{2}{*}{ Pooled SEM } \\
\hline & No phytic acid & Free phytic acid & Magnesium-potassium phytate & 0 & 1000 & \\
\hline$n$ & 16 & 16 & 16 & 24 & 24 & \\
\hline \multicolumn{7}{|c|}{ Indispensable amino acids } \\
\hline Arginine & 0.42 & $0.54^{*}$ & $0.55^{\star}$ & 0.52 & 0.49 & 0.05 \\
\hline Histidine & 0.23 & 0.30 & 0.33 & 0.31 & 0.27 & 0.04 \\
\hline Isoleucine & 0.35 & 0.40 & 0.42 & 0.41 & 0.37 & 0.04 \\
\hline Leucine & 0.57 & 0.69 & 0.70 & 0.68 & 0.63 & 0.07 \\
\hline Lysine & 0.51 & 0.63 & 0.61 & 0.60 & 0.57 & 0.06 \\
\hline Methionine & 0.15 & $0 \cdot 18$ & 0.19 & 0.19 & 0.16 & 0.02 \\
\hline Phenylalanine & 0.36 & 0.44 & 0.44 & 0.43 & 0.40 & 0.04 \\
\hline Threonine & 0.53 & $0.68^{*}$ & $0.68^{*}$ & 0.64 & 0.62 & 0.05 \\
\hline Tryptophan & 0.12 & 0.13 & 0.13 & 0.13 & 0.13 & 0.01 \\
\hline Valine & 0.48 & 0.57 & 0.59 & 0.56 & 0.53 & 0.06 \\
\hline \multicolumn{7}{|l|}{ Dispensable amino acids } \\
\hline Alanine & 0.59 & 0.70 & 0.72 & 0.69 & 0.66 & 0.06 \\
\hline Aspartate & 0.87 & 1.07 & 1.08 & 1.03 & 0.99 & 0.10 \\
\hline Cysteine & 0.26 & 0.30 & 0.30 & 0.29 & 0.29 & 0.02 \\
\hline Glutamate & 1.38 & 1.63 & 1.68 & 1.58 & 1.55 & 0.13 \\
\hline Glycine & $2 \cdot 18$ & $2 \cdot 56^{\star}$ & $2 \cdot 78^{\star}$ & 2.50 & 2.51 & 0.18 \\
\hline Proline & 0.72 & $0.94^{*}$ & $0.92^{*}$ & 0.83 & 0.89 & 0.06 \\
\hline Serine & 0.47 & $0.60^{*}$ & $0.62^{*}$ & 0.56 & 0.56 & 0.05 \\
\hline Tyrosine & 0.32 & 0.37 & 0.38 & 0.37 & 0.34 & 0.04 \\
\hline Total of all amino acids & 11.61 & $13 \cdot 93^{*}$ & $14.59^{*}$ & 13.47 & 13.28 & 0.98 \\
\hline
\end{tabular}

Mean values of the average of the 'Free phytic acid' and 'Magnesium-potassium phytate' groups were significantly different from those of the 'No phytic acid' group: ${ }^{\star} P<0.05$. $\ddagger$ For details of procedures, see Materials and methods section and Table 1. Values were calculated using excreta values that had been corrected for uric acid.

nutrients and also reduce their availability for absorption. In the present study, birds fed phytic acid had increased loss of mucin, sialic acid and some amino acids. Cowieson et al. ${ }^{(10)}$ reported similar findings when chickens were fed sodium phytate. Findings in the current study extend such observations to magnesium-potassium phytate, whose composition is close to that of the natural form of phytic acid. Birds fed magnesiumpotassium phytate showed increased excretion of mucin, sialic acid and some amino acids when compared with birds that were not fed phytic acid. In fact, birds fed magnesium-potassium phytate excreted more mucin than those fed free phytic acid. The mechanism by which phytates increase endogenous losses of mucin and amino acids is not fully understood.

In the present study, birds fed the two phytic acid forms showed an increase in mucin and sialic acid content of the excreta. The increase in mucin loss was greater with magnesium-potassium phytate feeding than with free phytic acid feeding. The patterns of change in crude mucin and sialic acid observed in the present study are similar. This would be expected because sialic acid is a major component of mucin and was determined from the crude mucin preparations. The exact mechanism by which phytic acid caused an increase in mucin production is not clear. One possible explanation could be related to roles of mucins in the digestive tract. Mucins are known to play important protective and lubrication roles in the digestive tract ${ }^{(23,24)}$. They have also been implicated to play other roles including adhesion, renewal, differentiation and signalling of epithelial cells ${ }^{(25)}$. Irritation of epithelial surfaces often results in increased mucin secretion ${ }^{(26,27)}$. It is possible that the increase in mucin production, observed when phytic acid was fed to birds, may be a response of the gut mucosa lining to irritation by the different phytic acid forms. If this explanation is true, it may imply that magnesium-potassium phytate feeding which elicited more mucin production than free phytic acid may be more irritating to the gut lining compared to free phytic acid. Therefore the presence of magnesium-potassium phytate would cause more mucin secretion to counter the irritation. Another explanation is related to the solubility of the two forms of phytic acid in the small intestine. Magnesium phytate, in particular, has been shown to be soluble below $\mathrm{pH} 5.5$ and its solubility rapidly declines when this $\mathrm{pH}$ is exceeded ${ }^{(28)}$. The uncomplexed free acid would be expected to be soluble at a much wider $\mathrm{pH}$ range than the magnesium-potassium phytate. The $\mathrm{pH}$ in the small intestine is alkaline and hence the solubility of magnesium-potassium phytate will be much reduced compared to that of the free acid. This solubility difference of the two forms will affect their susceptibility to breakdown by endogenous or exogenous phytase in the digestive tract. Magnesium-potassium phytate is likely to persist longer in the intestine and therefore it is more likely to cause more mucin release compared to the free acid.

Phytic acid feeding increased not only the loss of mucin but also that of threonine, proline and serine amino acids. The increased amino acid loss was extended to include arginine and glycine, along with threonine, proline and serine, when the amino acid loss was expressed as the proportion of endogenous crude protein. Increase in amino acid loss is a finding that is in agreement with that of Cowieson et al. ${ }^{(10)}$, who reported an increase in the loss of most of the amino acids measured when chickens were fed phytic acid. A more recent study by Cowieson and Ravindran ${ }^{(11)}$ has also reported increased flow of most of the amino acids at the ileum when birds were fed purified diets containing phytic acid. In contrast to the present study, the study by Cowieson and Ravindran ${ }^{(11)}$ did not show an increased loss of proline but, like the Cowieson et al. ${ }^{(10)}$ study, they did report increased loss or flow of threonine 
and serine. In the study by Cowieson et al. ${ }^{(10)}$, proline was not among the amino acids measured. The present study is more similar to the study by Cowieson et al. ${ }^{(10)}$. It would have been interesting to know how this particular amino acid behaved in their study. The major amino acids that constitute mucins include threonine, serine and proline in the major domain and cysteine in the minor domain ${ }^{(10,29)}$. Because phytic acid feeding increased mucin excretion in the chickens, the increased loss of threonine, proline and serine is most probably due to the increase in mucin excretion. The observation that these three major constituent amino acids of mucin showed increased loss when phytic acid was fed strongly suggests that the main mechanism by which phytates increase amino acid flow is by inducing an increase in mucin excretion. An increase in mucin secretion will directly cause an increase in amino acid flow because the mucin structure consists of a peptide core of various amino acids.

Phytate-induced increase in amino acid flow has previously been attributed primarily to compensatory oversecretion of digestive enzymes in response to their inhibition ${ }^{(30,31)}$. This explanation is mainly based on a number of in vitro studies that have indicated that phytates may, directly or indirectly, inhibit digestive enzymes such as pepsin ${ }^{(8,9)}$, lipase ${ }^{(6)}$, carboxypeptidase $\mathrm{A}^{(32)}$, chymotrypsin ${ }^{(33)}$ and $\alpha$-amylase ${ }^{(7)}$. The extent of such inhibition occurring in vivo has not been verified and remains largely speculative. If, however, there is appreciable in vivo phytate inhibition of these enzymes, it could lead to compensatory oversecretion of the inhibited enzymes and this may directly lead to increased endogenous amino acid losses. In particular, an oversecretion of pepsin would increase the presence of the enzyme in the stomach lumen and this has been shown to stimulate mucus secretion ${ }^{(34)}$. This increase in mucus secretion could result in increased mucin and amino acid flow. The contribution of compensatory oversecretion of enzymes to the phytate-induced increase in amino acid flow remains speculative until the extent of the in vivo phytate inhibition of digestive enzymes is known.

The finding that magnesium-potassium phytate caused greater mucin loss compared to free acid could have direct implications on the digestion of poultry diets containing plant ingredients, which may contain phytates. This is because magnesium and potassium are among the most predominant cations in the phytin molecule. Indeed magnesium-potassium phytates may be the major contributor to the anti-nutritional effects of feed phytates. Hence, it is beneficial to hydrolyse phytates in diets in order to reduce the endogenous losses they induce.

In the present study and a similar study by Cowieson et al. ${ }^{(10)}$, intact birds were used. Therefore, results of the effects of phytic acid from the two studies reflect what happened throughout the entire digestive tract with the possible modification of the endogenous amino acid flow by microflora in the lower digestive tract. Cowieson and Ravindran ${ }^{(11)}$, utilising ileal contents of birds, reported an increased flow of threonine and serine, two of the major mucin constituent amino acids, when birds were fed synthetic diets containing sodium phytate. This would indicate that the mucin effect of phytic acid is not only measurable at the end of the entire digestive tract but it is already present even at the level of the ileum. It would be interesting to apportion the mucin loss to the different sections of the gastrointestinal tract. For example, studies utilising intact and caecectomised birds could be useful in assessing the contribution of the caeca to the total mucin and amino acid losses. The influence of caecal microflora on total mucin loss may be affected by the amounts of mucins secreted in the different portions of the gastrointestinal tract. It is known that although mucus is secreted throughout the digestive tract, secretion varies with the section of the gastrointestinal section ${ }^{(35)}$. For example, the adherent mucus secretion gradually increases from the jejunum to the colon $^{(35)}$ and these regional differences could affect the relative influence of the caecum on the overall mucin loss.

In the present study, phytase supplementation did not change the endogenous loss of amino acids in chickens fed phytic acid. In contrast to the present study, Cowieson et al. ${ }^{(10)}$ reported that the increase in endogenous loss of sialic acid, amino acids and minerals, noted when chickens were fed phytate, was reduced when exogenous phytase was fed together with the phytate. More recently, Cowieson \& Ravindran ${ }^{(11)}$ have reported similar findings that phytase supplementation to a diet with added phytate reduced the amount of endogenous amino acid flow at the ileum. Although the study by Cowieson et al. ${ }^{(10)}$ and the present study are quite similar, the difference in the phytase supplementation response in the two studies may have been due to the bird ages ( $6 v .10$ weeks) and the different sources of phytase used. Nevertheless, the action of phytase (myo-inositol-hexakisphosphohydrolase), a fairly specific phosphohydrolase for phytate $^{(36)}$, is well documented. It hydrolyses ester bonds between inositol and phosphate groups in the phytate molecule to release inositol monophosphate and orthophosphate via inositol penta- to mono-phosphates as intermediary products ${ }^{(14,36)}$. By hydrolysing phytate, exogenous phytase removes phytate whose presence seems to induce an increase in endogenous amino acid losses. This observation underscores the importance of using supplemental phytase in diets for monogastric animals to reduce anti-nutritional effects of phytates.

Birds are classified as uricotelic animals because they get rid of excess nitrogen by converting it into uric acid before excreting it. In the present study, chickens fed phytic acid showed a trend towards increased excretion of uric acid. This may be an indication that, somehow, inositol hexaphosphate or its breakdown products may be increasing uric acid synthesis. Inositol phosphates are well-known second messengers in cells ${ }^{(37,38)}$ and it is possible that they could be playing a role in up-regulating the uric acid synthetic pathway in birds.

In summary, intubating chickens with magnesium-potassium phytate or free phytic acid increased the loss of mucin and sialic acid with the loss of mucin being greater with the magnesium-potassium phytate than with free phytic acid treatment Phytic acid feeding also increased endogenous loss of threonine, proline and serine. The findings agree with the hypothesis that the different forms of phytic acid would have different effects on endogenous losses. In conclusion, the form of phytic acid fed to chickens affects the extent of mucin and endogenous amino acid losses from the gastrointestinal tract.

\section{Acknowledgements}

The research was conducted at Purdue University, IN, USA. The authors wish to thank Pat Jaynes for her technical assistance, and Sunday Adetayo Adedokun, Ryan Dilger, Brian Ford and Josh Jendza for their help during this study. Funding provided by the Midwest Poultry Consortium (St. Paul, MN, USA) is gratefully acknowledged. This study is journal 
paper number 2007-18213 of the Purdue University Agricultural Research Program. The authors declare that there was no conflict of interest in this study. All the authors contributed to the planning and execution of this study. E. M. O. was involved in the design and execution of the study and also drafting of the manuscript and E. K. A. and O. A. were involved in the design and revision of the manuscript.

\section{References}

1. Graf E (1983) Applications of phytic acid. J Am Oil Chem Soc 60, $1861-1867$.

2. Lott JNA, Ockenden I, Raboy V \& Batten GD (2000) Phytic acid and phosphorus in crop seed and fruits: a global estimate. Seed Sci Res 10, 11-33.

3. Costello AJR, Glonek J \& Myers TC (1976) ${ }^{31} \mathrm{P}$ nuclear magnetic resonance-pH titrations of myo-inositol hexaphosphate. Carbohydr Res 46, 159-171.

4. Erdman JW Jr (1979) Oilseed phytates: nutritional implications. J Am Oil Chem Soc 56, 736-741.

5. Angkanaporn K, Choct M, Bryden WL \& Annison EF (1994) Effects of wheat pentosans on endogenous amino acid losses in chickens. J Sci Food Agric 66, 399-404.

6. Knuckles BE (1988) Effect of phytate and other myo-inositol phosphate esters on lipase activity. J Food Sci 53, 250-252.

7. Deshpande SS \& Cheryan M (1984) Effects of phytic acid, divalent cations, and their interactions on $\alpha$-amylase activity. J Food Sci 49, 516-524.

8. Camus M \& Laporte JC (1976) Inhibition de la protéolyse pepsique par le blé. Rôle de l'acide phytique des issues. Ann Biol Anim Biochim Biophys 16, 719-729.

9. Vaintraub IA \& Bulmaga VP (1991) Effect of phytate on the in vitro activity of digestive proteinases. J Agric Food Chem 39, 859-861.

10. Cowieson AJ, Acamovic T \& Bedford MR (2004) The effects of phytase and phytic acid on the loss of endogenous amino acids and minerals from broiler chickens. Br Poult Sci 45, 101-108.

11. Cowieson AJ \& Ravindran V (2007) Effect of phytic acid and microbial phytase on the flow and amino acid composition of endogenous protein at the terminal ileum of growing broiler chickens. Br J Nutr 98, 745-752.

12. Adeola O, Ragland D \& King D (1997) Feeding and excreta collection techniques in metabolizable energy assays for ducks. Poult Sci 76, 728-732.

13. NRC (1994) Nutrient Requirements of Poultry. Washington, DC: National Academy Press.

14. Reddy NR, Sathe SK \& Salunkhe DK (1982) Phytates in legumes and cereals. Adv Food Res 28, 1-92.

15. AOAC (2000) Official Methods of Analysis. Washington, DC: Association of Official Analytical Chemists.

16. Lien KA, Sauer WC \& Fenton M (1997) Mucin output in ileal digesta of pigs fed a protein-free diet. Z Ernahrungswissenschaft 36, 182-190.

17. Surangkul D, Pothacharoen $\mathrm{P}$, Suttajit $\mathrm{M}$ \& Kongtawelert $\mathrm{P}$ (2001) A periodate-resorcinal microassay for the quantitation of total sialic acid in human serum. Chiang Mai Med Bull 40, $111-118$

18. Jourdian GW, Dean LD \& Roseman S (1971) The sialic acids: XI. A periodate-resorcinol method for the quantitative estimation of free sialic acids and their glycosides. $J$ Biol Chem 246, 430-435.
19. Bhavanandan VP \& Sheykhnazari M (1993) Adaptation of the periodate-resorcinol method for determination of sialic acid to a microassay using microtiter plate reader. Anal Biochem 213, $438-440$.

20. Gendler SJ \& Spicer AP (1995) Epithelial mucin genes. Annu Rev Physiol 57, 607-634.

21. Lang T, Hansson GC \& Samuelsson T (2007) Gel-forming mucins appeared early in metazoan evolution. Proc Natl Acad Sci U S A 104, 16209-16214.

22. Wise A (1983) Dietary factors determining the biological activities of phytates. Nutr Abstr Rev Clin Nutr 53, 791-806

23. Kutchai HC (1998) The gastrointestinal system. In Physiology, 4th ed., pp. 587-674 [RM Berne, MN Levy, BM Koeppen and BA Stanton, editors]. St Louis, MO: Mosby.

24. Garrett RH \& Grisham CM (1999) Biochemistry, 2nd ed. Fort Worth, TX: Saunders College Publishing, Harcourt Brace College Publishers.

25. Andrianifahanana M, Moniaux N \& Batra SK (2006) Regulation of mucin expression: mechanistic aspects and implications for cancer and inflammatory diseases. Biochim Biophys Acta 1765, 189-222.

26. Forstner JF (1978) Intestinal mucins in health and disease. Digestion 17, 234-263.

27. Specian RD \& Neutra MR (1980) Mechanism of rapid mucus secretion in goblet cells stimulated by acetylcholine. J Cell Biol 85, 626-640.

28. Cheryan M, Anderson FW \& Grynspan F (1983) Magnesiumphytate complexes: effect of $\mathrm{pH}$ and molar ratio on solubility characteristics. Cereal Chem 60, 235-237.

29. Alberts B, Bray D, Lewis J, Raff M, Roberts K \& Watson J (1989) Molecular Biology of the Cell, 2nd ed. New York: Garland Publishing.

30. Grant G (1989) Anti-nutritional effects of soybean: a review. Prog Food Nutr Sci 13, 317-348.

31. Ahmed AE, Smithard R \& Ellis M (1991) Activities of enzymes of the pancreas, and the lumen and mucosa of the small intestine in growing broiler cockerels fed on tannin-containing diets. $\mathrm{Br} \mathrm{J}$ Nutr 65, 189-197.

32. Martin CJ \& Evans WJ (1989) Phytic acid-enhanced metal ion exchange reactions: the effect on carboxypeptidase A. J Inorg Biochem 35, 267-288.

33. Sathe SK \& Sze-tao KWC (1997) Effects of sodium chloride, phytate and tannin on in vitro proteolysis of phaseolin. Food Chem 59, 253-259.

34. Munster DJ, Bagshaw PF \& Wilson JG (1987) Peptic erosion of gastric mucus in the rat. Comp Biochem Physiol A Mol Integr Physiol 87, 509-513.

35. Atuma C, Strugala V, Allen A \& Holm L (2001) The adherent gastrointestinal mucus gel layer: thickness and physical state in vivo. Am J Physiol Gastrointest Liver Physiol 280, G922-G929.

36. Liu B, Rafiq A, Tzeng Y \& Rob A (1998) The induction and characterization of phytase and beyond. Enzyme Microb Technol 22, 415-424.

37. Irvine RF, Letcher AJ, Lander DJ \& Berridge MJ (1986) Specificity of inositol phosphate-stimulated $\mathrm{Ca}^{2+}$ mobilization from Swiss-mouse 3T3 cells. Biochem J 240, 301-304.

38. Nussenzveig DR, Thaw CN \& Gershengorn MC (1994) Inhibition of inositol phosphate second messenger formation by intracellular loop one of a human calcitonin receptor. $J$ Biol Chem 269, 28123-28129. 